\title{
Exploring PechaKucha in EFL Learners' Public Speaking Performances
}

\author{
Zharkynbekova, Sholpan; Zhussupova, Roza; Suleimenova, Shynara \\ Department of Philology, Eurasian National University, Astana, Kazakhstan
}

\begin{abstract}
The purpose of the study is to examine PechaKucha helps EFL Learners' to enhance their Public Speaking Performances and to explore useful information regarding the PechaKucha implementation as a learning tool. This study was conducted with sixty students at the University level. They were assigned into two groups randomly as experimental and control. The experimental teaching put into practice PechaKucha in accordance with public speaking activities. Meanwhile, the control group was given conventional speaking lessons only. To assess the performance the initial and post-testing by means of analytic scoring rubrics were used. In addition, a survey questionnaire was administrated to experimental group to examine their attitudes towards using Pecha Kucha in improving public speaking skills.
\end{abstract}

The results showed that themost number of students in the experimental group scored higher points than the control group. It can be concluded that the average performance of experimental group on the speaking public presentation skills posttesting increased in 10\% comparing with that of the control group. Questionnaire's results reported that EFL learners in the experimental group mostly conveyed positive attitudes. This study recommended that EFL students need to be familiarized and trained with the use of PechaKucha technology into their EFL teaching.

Keywords: Public Speaking Performance, PechaKucha, Rubrics, EFL. 


\section{Introduction}

Technology has changed the nature of instruction and learning. Teachers are exploring digital technologies to make learning more effective and engage students actively. Technology promotes socially active language in multiple authentic contexts due to its "accessibility, flexibility, connectivity speed and independence of methodological approach" (Gonzalez, J. A., 2009). More importantly with interactive web resources that provide the benefits of networking and real time communication the students can continue to learn the target language and enhance their cultural understanding outside the classroom (Bush M. D., 2007). The digital resources allow teachers to create new techniques, as well as reevaluate and improve the more traditional techniques that helps bring the target culture into the classroom. Methodologists argue that language learning should occur in a dynamic and active manner (Pitler H.,2006, Meadows D., 2003, Macquire J.1998, Razmia M, Pouralib S, Nozad S., 2014). Technology-based activities together with an inquiry learning approach allow students to interact directly with the second language and its culture without time and place restrictions and to explore and construct a deeper understanding of target language cultural knowledge according to Ellis R. (1986), cited in Dema O., Aleidine J. (2012) a lot can be done with Powerpoint from creating basic presentations to photo albums, timed presentations with recordings, hyperlinked games and fascinating PechaKucha (PK). It is important that the research carried out by the GIAPEL group Villanueva, Ruiz-Madrid \& Luzon (2008 and 2010) relied on the assumption that when "working with Web-mediated texts, students need to become wreaders and develop strategies which involve the integration of the reading and writing competence into a single wreading competence which means interaction with the text in all the ways for constructing meaning in a digital environment".

Originally PechaKucha is the Japanese word for conversation or "chit chat" which was created by two architects in Tokyo who were tired of dreadful PowerPoint presentations. PechaKucha is designed to force speakers to prepare shorter, more creative, and more polished PowerPoint presentation. More importantly designing a PechaKucha presentation motivates speakers to think about their subjects in very different ways. A presentation is created using PowerPoint or any other presentation software. Presenters are only allowed 20 slides and those slides must automatically advance every 20 seconds thus the " $20 \times 20$ " label. Consequently, presentations should never be longer than 6 minutes 40 seconds because of this format, the PowerPoint slideshow must depend on visuals, rather than textheavy slides. This is one of the best characteristics since speakers often abuse text in slideshows. Seeing PK facilitated by Jeremy Harmer at the 46th Annual International IATEFL Conference \& Exhibition in Glasgou, Scotland, his presentations outstood having structure with a perfect introduction and conclusion and an internal structure clear main points, transitions that guided the audience through the slideshow. Hence the words and the 
visual aid complement each other rather than just mirroring each other. Presentations are expected to be polished, professional, and engaging because of the time constraints, the auto-advancing slides, and the format, speakers spend more time planning and practicing their presentations as Scott Thornbury acted in his Youtube presentations "Exposure Immersion and Technology" (2015). Audiences are more likely to be engaged. Consequently, speakers need experience presenting their ideas in a short period of time and in a more creative, engaging way. Because of the short presentation, the audience should have plenty of time to ask questions and make comments about the presentation. PK mainstreams such language abilities as fluent speaking, public presentations skills, mastering computer assisted learning. Every ability in its turn has significant features which are necessary for students to perform brilliantly so that to be ready for professional endeavor and possess self-confidence and be assured professionally.

\section{Methodology}

\subsection{Participants' profile}

Methodological basis of the research are integrated general and specific methods, including observation, study and synthesis of experience, questioning, experiment and critical analysis of scientific and methodical literature on the problem and statistical analysis. Firstly we learned information on fundamentals of PK: its history of development, ways of implementation and structural basis. The practical part of the research was based on designing lessons during 5 weeks and their realization in Kazakhstani English language classroom and then was presented an analysis of the experiment from the three sides: to the impact on speaking skills development, public presentations skills and average academic performance.

Our research was held in the Eurasian National University with the $2 \mathrm{~d}$ year students of the speciality "Foreign Language: Two Foreign Languages" aged 19-20. There were 3 groups totally 60 students including 18 males and 42 females. Each group is divided into two subgroups due to the academic aptitude: subgroup " $A$ " and subgroup "B", 10 students in each. Subgroup "A" overall has the same marks and level of knowledge as subgroup "B". The research was held in group "B" which called experimental with implementing PK while group "A" control has a traditional teaching approach. Students are quite united; they respect and value each other. The academic proficiency of the whole group is high enough. There is no evident leader in the class. However, there are a couple of girls who eagerly arrange all class activities and keep the students united. They are the most responsible persons who are ready to help with any arrangement. Overall the students are wellmannered. They do not unitize obscene language, at least, in teacher's presence. At the lessons the part of the group is active and loud, another part is quiet silent. Teacher has to 
make effort to arouse them from the indifference. Subject-matter of texts and assignments meet the students' needs and interests in compliance with claimed age. Majority of students have B1 level of English proficiency.

\subsection{Pre-Experimental Procedures}

The purpose of the PK project was targeted as to improve speaking fluency and coherence, to develop lexical and grammatical accuracy and make better pronunciation. The descriptors as fluency and coherence, lexical resource, grammatical range and accuracy, and pronunciation are used worldwide in assessing IELTS speaking results. We added Body Language as set aparted descriptor for maintaining public performances skills. Body Language includes nonverbal communication, physical presentation and visuals (Appendix). So beforehand during the first week we observed the experimental and control groups, gave them survey questionaries about their speaking skills in public and selfevaluation. Furthermore the initial test consisting of 2 sections was elaborated to analyze students' speaking skills in both groups. The checking was conducted during one academic hour at the first week, besides, in experimental and control groups were 30 students in each. So every descriptor counted in number of students according to their points of speaking descriptors. The results of the initial testing are illustrated in Tables 1 and 2. 
Zharkynbekova, Sh.; Zhussupova, R.; Suleimenova, Sh.

\begin{tabular}{|c|c|c|c|c|}
\hline $\begin{array}{l}\text { Speaking Descriptors/ } \\
\text { Points\%/ Number of students }\end{array}$ & $\begin{array}{c}\text { Fluency } \\
\text { and } \\
\text { coherence }\end{array}$ & $\begin{array}{c}\text { Lexical } \\
\text { Grammatical } \\
\text { accuracy }\end{array}$ & Pronunciation & Body language \\
\hline
\end{tabular}

\begin{tabular}{|l|cccc|}
$\mathbf{1 0 0 - 8 0 \%}$ & 8 & 10 & 8 & 7 \\
$\mathbf{7 9 - 6 0 \%}$ & 11 & 10 & 12 & 9 \\
$\mathbf{5 9 - 4 0 \%}$ & 5 & 3 & 5 & 7 \\
$\mathbf{3 9 - 2 0 \%}$ & 4 & 3 & 3 & 4 \\
$\mathbf{1 9 - 0 \%}$ & 2 & 1 & 2 & 3
\end{tabular}

Table 1. The Control "A" subgroup students' public speaking initial test results

$\begin{array}{lcccc}\text { Speaking Descriptors/ } & \begin{array}{c}\text { Fluency } \\ \text { and } \\ \text { coherence }\end{array} & \begin{array}{c}\text { Lexical } \\ \text { Grammatical } \\ \text { accuracy }\end{array} & \text { Pronunciation } & \text { Body language } \\ \text { Points } \% / \text { Number of students } & & \end{array}$

\begin{tabular}{|l|llll|}
$\mathbf{1 0 0 - 8 0 \%}$ & 7 & 8 & 8 & 5 \\
$\mathbf{7 9 - 6 0 \%}$ & 9 & 8 & 10 & 8 \\
$\mathbf{5 9 - 4 0 \%}$ & 6 & 5 & 7 & 6 \\
$\mathbf{3 9 - 2 0 \%}$ & 4 & 5 & 3 & 7 \\
$\mathbf{1 9 - 0 \%}$ & 4 & 4 & 2 & 4
\end{tabular}

Table 2. The Experimental "B" subgroup students' public speaking initial test results

As we can see in Tables 1 and 2 analysing the first descriptor - fluency and coherence control group has better results as 8 and 7 (100-80\%), 11 and 9 (79-60\%), 2 and 4 (19-0\%) correspondingly. Regarding lexical and grammatical accuracy also students from control group get higher points than experimental one: 100-80\% points have 10 students in group "A" while only 8 students in group "B". Besides 4 students from experimental group have the lowest results. Nevertheless, students with good pronunciation $100-80 \%$ and next points are observed in both group equally. Also, the number of students in control group in accordance with body language descriptor is slightly higher than in experimental one. Hence observing speaking initial testing results of control and experimental groups the highest points of all descriptors are occurred in control " $\mathrm{B}$ " group.

\subsection{Experimental Procedures}

Totally our experimental teaching lasted 5 weeks by reference to syllabus we had English lessons 3 hours weekly. In fact the experimental group "B" implemented PechaKucha in accordance with speaking activities. Meanwhile, control group "A" had parallel lessons 
with the same topics on given conventional speaking lessons only. It was important for our experiment to have a complete picture of the positive and negative aspects of the PK using in classroom setting that's why results were assessed in the pre- and post-testing due to analytic scoring rubrics. Firstly, we explained PK characteristics and discussed its implementation at the English classrooms according to the syllabus during the first week. Moreover we introduced analytic scoring rubrics as an assessment. We started by doing a presentation ourselves about something that relates to our lifestyle. The students were encouraged to choose a topic which has personal significance to them so that the whole class could find out more about each other through the presentations. So the topics under experiment were "Art and Literature in Our Life", "Performance art", "Green issues". We provided examples as good online examples using official PechaKucha website at: http://www.pecha-kucha.org/. Then, during the second week we slightly increased the time for each slide and allowed longer presentations so that to prepare them to speak fluently and master public speaking performance and relieving a stress of speaking in public. At the third week we asked students to try to use a 'Pecha Kucha'format: 20 slides by 20 seconds which was more rigid but often more enjoyable. Next, we complicated tasks for students with taking their own photographs for the presentation, encouraging students to orally cite sources and providing audience handouts with full citations as a part of the assignment during the $4^{\text {th }}$ week. The main purpose was to create interest in their topics among the audience and get students thinking critically and speaking relaxed about topics. This format was centered on the idea of audience analysis and, therefore, asked for speakers to think about the most critical components of the topic, the best way to visually represent the ideas, and the most interactive way to present the material verbally and nonverbally. Finally, at the $5^{\text {th }}$ week we dicussed feedback of implementation PK and the experimental group completed questionnaire and analysed scoring rubrics.

\subsection{Experimental Results}

Post-test was prepared using initial test structure, thus, it consists of 2 speaking parts in both groups so that to compare the improvement of speaking skills in public performances. In both groups were the equal number of students: 30. As it was mentioned above, the descriptors were as follows: Fluency and cohererence, Lexical resource, Grammatical range and accuracy, Pronunciation, Body Language. In accordance with initial testing every criterion of the post experimental testing counted in number of students depending on their points of speaking descriptors. The results of the post testing are illustrated in Tables 3, 4 . 


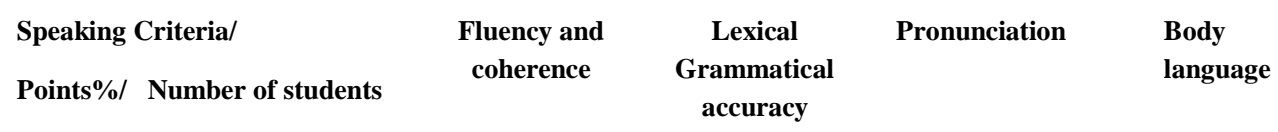

\begin{tabular}{|c|c|c|c|c|}
\hline $100-80 \%$ & 7 & 10 & 8 & 8 \\
\hline $79-60 \%$ & 10 & 9 & 12 & 7 \\
\hline $59-40 \%$ & 7 & 4 & 5 & 7 \\
\hline $39-20 \%$ & 4 & 3 & 3 & 4 \\
\hline $19-0 \%$ & 2 & 1 & 2 & 3 \\
\hline \multicolumn{5}{|c|}{ Table 3. The Control "A" subgroup students' public speaking post test results } \\
\hline $\begin{array}{l}\text { Speaking Criteria/ } \\
\text { Points\%/ Number of students }\end{array}$ & $\begin{array}{c}\text { Fluency and } \\
\text { coherence }\end{array}$ & $\begin{array}{c}\text { Lexical } \\
\text { Grammatical } \\
\text { accuracy }\end{array}$ & Pronunciation & $\begin{array}{l}\text { Body } \\
\text { language }\end{array}$ \\
\hline $100-80 \%$ & 8 & 10 & 9 & 8 \\
\hline $79-60 \%$ & 10 & 9 & 10 & 8 \\
\hline $59-40 \%$ & 6 & 5 & 7 & 7 \\
\hline $39-20 \%$ & 5 & 4 & 3 & 6 \\
\hline $19-0 \%$ & 1 & 2 & 1 & 1 \\
\hline
\end{tabular}

Table 4. The Experimental "B" subgroup students' public speaking post test results

As the Tables 3 and 4 denote there are differences between experimental and control groups regarding fluency and coherence on initial tests and posttests: according to 100-80\% points in group "B" 7 and 8 , in group "A" 8 and 7 correspondingly. But according to 39-20\% points the number of students of the first descriptor in the experimental group -4 and 5- is higher than in control -4 and 5. The highest positive deviation is observed in experimental group regarding pronunciation improvement $(100-80 \%, 19-0 \%)$ which is higher than in control group. Therefore, there is no significant correlation on lexical and grammatical accuracy in both groups. According to the Tables 3 and 4, less students of control group get points (19-0\%) of body language descriptor.

But actually in comparison with the control group, the moderated average variance of the experimental group is higher in all descriptors. The results point out that all participants of the control group had made some improvements after the study but the improvement was not as big as the one made by the experimental group learners. The average variance of the experimental group was obviously superior to that of the control group showing that the PK technique could effectively enhance the public speaking performances of the students. Regarding the results of initial testing and posttest we can observe dynamics of the first descriptor as fluency and coherence through experimental group only: 100-80\%- 7 and 8 students correspondingly, 79-60\% - 9 and 10 students, 19-0\% - 4 and 1. In addition, the 
second descriptor as lexical and grammatical accuracy in post-test were 10 students with $100-80 \%$ comparing in initial 8 students, only 2 students get 19-0\% instead of 4 in initial. Therefore, it can be concluded that the average performance of experimental group on the speaking public presentation skills posttesting increased in $10 \%$ comparing with that of the control group. The results showed that the students in the experimental group scored significantly higher than the control group. Aditionally questionnaire's results reported that EFL learners in the experimental group mostly conveyed positive attitudes. This study recommended that EFL students need to be familiarized and trained with the use of PechaKucha technology into their EFL teaching.

\section{Findings}

The research focused on how to implement PK techniques in the classroom, describing its pecularities, and explaining teacher roles and student tasks; therefore, this research gives a clear picture of how to integrate PK into University levels. Consequently, the new knowledge generated by this research can be implemented corresponding future educational policy. Firstly, in the practical part the results of the initial test in both control and experimental groups were presented. Secondly, the sequence of topics were generated using PK format have been created in the past to help educators achieve better learning outcomes on speaking skills in public performances and probed experimentally. Thirdly, the post-test was held and the findings indicate that the learners in the experimental group, initially having inferior results, noticeably improved performance according to traditional grading system and speaking skills criterion; the students in the control group have showed practically the same results as in initial test. As a result PK significantly improves students' speaking skills in public much more than the traditional way of teaching. Thus, the experimental results of students' performance confirm PK as learning tool can engage students in the practical environment. PK makes practice and training more engaging, diverse, and customized to their needs and challenges. Through the process of PK students can turn narratives into multimedia productions to develop their speaking skills fluently and act more assured. The technique of PechaKucha can be used effectively in Kazakhstani classroom setting to improve English language acquisition. What is more students from experimental group presented stories using digital images, photographs, video, animation, sound, music, text and a narrative voice boosted the positive motivating impression. Thus research has emphasized that using PechaKucha to communicate and to learn therefore involves being able to understand the new discourse practices for constructing new knowledge. 


\section{Conclusion}

The innovative PechaKucha as new learning tool allows teachers to create and improve the more traditional techniques into the classroom. Based on the main aim of this research in investigating the peculiarities of PK and proving the effectiveness of using this technological tool experimentally in teaching a foreign language we summarise that surely PK is a significantly essential part of any English classroom focusing on the principle of cooperative learning in public speaking performances. This study contributes to new understandings of how to create authentic learning context that can be used in a range of educational settings. We would like to sum up with words that our research work is done in Kazakhstani classroom and its results have an important scientific significance and practical value for English teachers at any schools, University and language courses worldwide.

\section{References}

Gonzalez, J. A. (2009). Technology and culture in the language class: Adding another ingredient to the old dilemma and a taxonomy and a database structure. AsiaCall Online Journal. №4. 58-66

Bush M. D. (2007) Facilitating the integration of culture and vocabulary learning: The categorization and use of pictures in the classroom. Foreign Language Annals. №4.727745

Pitler, H. (2006) Viewing technology through three lenses. Principal. №5.38-42.

Meadows, D. (2003) Digital storytelling: research-based practice in new media. Visual Communication. №2. 189-193

Macquire, J. (1998) The power of personal storytelling: Spinning tales to connect with others. Putnam. New York. 272 p.

Razmia, M, Pouralib, S, Nozad, S. (2014) Digital Storytelling in EFL Classroom (Oral Presentation of the Story): A Pathway to Improve Oral Production// Procedia. - Social and Behavioral Sciences. №98. 1541-1544

Ellis R. (1986) Understanding second language acquisition. Oxford University Press. USA. $327 \mathrm{p}$.

Dema O., Aleidine J. (2012) Teaching culture in the 21st century language classroom. Central States Conference on the Teaching of foreign languages. 75-91

Luzón, M.J., Ruiz-Madrid, M.N. \& Villanueva, M.L. (2010). Learner Autonomy in digital environments: Conceptual framework. Chapter 1 in the book: Digital Genres, New Literacies and Autonomy in Language Learning. Cambridge Scholars Publishing. 1-25.

Harmer J. (2012) Glasgow Online. The 46th Annual International IATEFL Conference \& Exhibition. http://iatefl.britishcouncil.org/2012/sessions/2012-03-22/pecha-kucha-part

Thornbury S. (2015). Exposure Immersion and Technology. Youtube, Education, 4 November, 2015 


\section{Appendix}

\section{RUBRICS}

\begin{tabular}{|c|c|c|c|c|}
\hline POINTS & Fluency and coherence & $\begin{array}{l}\text { Lexical resource, Grammatical range and } \\
\text { accuracy }\end{array}$ & Pronunciation & Body Language \\
\hline $100-80 \%$ & $\begin{array}{l}\text { *speaks fluently with } \\
\text { only occasional repetition } \\
\text { or self correction; } \\
\text { hesitation is usually } \\
\text { content-related and only } \\
\text { rarely to search for } \\
\text { language, - develops } \\
\text { topics coherently and } \\
\text { appropriately }\end{array}$ & $\begin{array}{l}\text { - uses a wide vocabulary resource readily and } \\
\text { flexibly to convey precise meaning, - uses } \\
\text { less common and idiomatic vocabulary } \\
\text { skillfully, with occasional inaccuracies } \\
\text { - uses paraphrase effectively as required, } \\
\text { uses a wide range of structures flexibly, } \\
\text { produces a majority of error-free sentences } \\
\text { with only very occasional inappropriacies or } \\
\text { basic/non-systematic errors }\end{array}$ & $\begin{array}{l}\text { - uses a wide range of } \\
\text { pronunciation features } \\
\text { - sustains flexible use of } \\
\text { features, with only occasional } \\
\text { lapses } \\
\text { - is easy to understand } \\
\text { throughout; L1 accent has } \\
\text { minimal effect on } \\
\text { intelligibility }\end{array}$ & $\begin{array}{lr}\text { Excellent } & \text { posture } \\
\text { with no swaying. } \\
\text { Gestures } \\
\text { smooth are } \\
\text { appropriate. } \\
\text { There is no } \\
\text { fidgeting. The } \\
\text { speaker appears } \\
\text { completely at ease. }\end{array}$ \\
\hline $79-60 \%$ & $\begin{array}{l}\text { *speaks at length without } \\
\text { noticeable effort or loss } \\
\text { of coherence } \\
\text { - may demonstrate } \\
\text { language-related } \\
\text { hesitation at times, or } \\
\text { some repetition and/or } \\
\text { self-correction a and } \\
\text { - uses a range of } \\
\text { connectives with } \\
\text { discourse markers wibity } \\
\text { some flexibility }\end{array}$ & $\begin{array}{l}\text { - uses vocabulary resource flexibly to discuss } \\
\text { a variety of topics, - uses some less common } \\
\text { and idiomatic vocabulary and shows some } \\
\text { awareness of style and collocation, with } \\
\text { some inappropriate choices, }- \text { uses } \\
\text { paraphrase effectively } \\
\text { - uses a range of complex structures with } \\
\text { some flexibility } \\
\text { - frequently produces error-free sentences, } \\
\text { though some grammatical mistakes persist }\end{array}$ & $\begin{array}{l}\text { - uses a wide range of } \\
\text { pronunciation features } \\
\text { - sustains flexible use of } \\
\text { features, with only occasional } \\
\text { lapses } \\
\text { - is easy to understand } \\
\text { throughout; L1 accent has } \\
\text { effect on intelligibility }\end{array}$ & $\begin{array}{l}\text { Speaker usually } \\
\text { maintains good } \\
\text { posture, but may } \\
\text { sway or lean on the } \\
\text { podium. There is a } \\
\text { small amount of } \\
\text { fidgeting. There are } \\
\text { a few gestures. }\end{array}$ \\
\hline $59-40 \%$ & $\begin{array}{l}\text { - is willing to speak at } \\
\text { length, though may lose } \\
\text { coherence at times due to } \\
\text { occasional repetition, } \\
\text { self-correction or } \\
\text { hesitation } \\
\text { - uses a range of } \\
\text { connectives and } \\
\text { discourse markers but not } \\
\text { always appropriately }\end{array}$ & $\begin{array}{l}\text { *has a wide enough vocabulary to discuss } \\
\text { topics at length and make meaning clear in } \\
\text { spite of inappropriacies } \\
\text { - generally paraphrases successfully, *uses a } \\
\text { mix of simple and complex structures, but } \\
\text { with limited flexibility } \\
\text { - may make frequent mistakes with complex } \\
\text { structures though these rarely cause } \\
\text { comprehension problems }\end{array}$ & $\begin{array}{l}\text { *uses a range of pronunciation } \\
\text { features with mixed control } \\
\text { - shows some effective use of } \\
\text { features but this is not } \\
\text { sustained } \\
\text { - can generally be understood } \\
\text { throughout }\end{array}$ & $\begin{array}{l}\text { Speaker leans on } \\
\text { the podium and/or } \\
\text { fidgets. } \\
\text { There was very } \\
\text { little gesturing } \\
\text { and/or movement. }\end{array}$ \\
\hline $39-20 \%$ & $\begin{array}{l}\text { *usually maintains flow } \\
\text { of speech but uses } \\
\text { repetition, self-correction } \\
\text { and/or slow speech to } \\
\text { keep going, - may over- } \\
\text { use certain connectives } \\
\text { and discourse markers } \\
\text { - produces simple speech } \\
\text { fluently, but more } \\
\text { complex communication } \\
\text { causes fluency problems }\end{array}$ & $\begin{array}{l}\text { *manages to talk about familiar and } \\
\text { unfamiliar topics but uses vocabulary with } \\
\text { limited flexibility, } \cdot \text { attempts to use } \\
\text { paraphrase but with mixed success, } \\
\text { *produces basic sentence forms with } \\
\text { reasonable accuracy, } \bullet \text { uses a limited range of } \\
\text { more complex structures, but these usually } \\
\text { contain errors and may cause some } \\
\text { comprehension problems }\end{array}$ & $\begin{array}{l}\text { *uses a range of pronunciation } \\
\text { features with mixed control } \\
\text { - shows some effective use of } \\
\text { features but this is not } \\
\text { sustained } \\
\text { - can generally be understood } \\
\text { throughout, though } \\
\text { mispronunciation of } \\
\text { individual words or sounds } \\
\text { reduces clarity at times }\end{array}$ & $\begin{array}{l}\text { Speaker leans on } \\
\text { the podium and/or } \\
\text { fidgets. } \\
\text { There is no } \\
\text { gesturing and/or } \\
\text { movement. }\end{array}$ \\
\hline $19-0 \%$ & $\begin{array}{l}\text { *cannot respond without } \\
\text { noticeable pauses and } \\
\text { may speak slowly, with } \\
\text { frequent repetition and } \\
\text { self-correction } \\
\text { - links basic sentences } \\
\text { but with repetitious use } \\
\text { of simple connectives } \\
\text { and some breakdowns in } \\
\text { coherence }\end{array}$ & $\begin{array}{l}\text { *is able to talk about familiar topics but can } \\
\text { only convey basic meaning on unfamiliar } \\
\text { topics and makes frequent errors in word } \\
\text { choice, } \cdot \text { rarely attempts paraphrase } \\
\text { - produces basic sentence forms and some } \\
\text { correct simple sentences but subordinate } \\
\text { structures are rare, } \cdot \text { errors are frequent and } \\
\text { may lead to misunderstanding }\end{array}$ & $\begin{array}{l}\text { *uses a limited range of } \\
\text { pronunciation features, - } \\
\text { attempts to control features } \\
\text { but lapses are frequent }\end{array}$ & $\begin{array}{lr}\text { Tension and } \\
\text { nervousness are } \\
\text { obvious and the } \\
\text { speaker } & \text { has } \\
\text { difficulty } & \\
\text { recovering from } \\
\text { mistakes. }\end{array}$ \\
\hline
\end{tabular}

